\title{
High Dose Tamoxifen in the Treatment of Recurrent High Grade Glioma: A Report of Clinical Stabilization and Tumour Regression
}

\author{
Gordon Baltuch, George Shenouda, Adrian Langleben and Jean-Guy Villemure
}

\begin{abstract}
We present a case of recurrent glioma, previously treated with maximal surgery and radiation in which a high dose of tamoxifen has stabilized the tumour clinically and has resulted in it's radiologic regression. Given tamoxifen's relative lack of toxicity, it might serve as a useful adjuvant in the treatment of recurrent glioma.

RÉSUMÉ: Le tamoxifène à haute dose dans le traitement du gliome récidivant: compte rendu d'un cas de stabilisation clinique et de régression de la tumeur. Nous présentons un cas de gliome récidivant traité antérieurement par chirurgie et irradiation maximales, chez qui le tamoxifène à hautes doses a amené une stabilisation clinique et une régression radiologique de la tumeur. Vu l'absence relative de toxicité du tamoxifène, ce médicament pourrait être un adjuvant utile dans le traitement du gliome récidivant.
\end{abstract}

Can. J. Neurol. Sci. 1993; 20: 168-170

Recurrent high grade gliomas have a very poor prognosis. These patients have received maximal surgery and irradiation, and are usually offered either supportive care or experimental protocols. These experimental therapies include immunotherapy, ${ }^{1}$ intra-arterial chemotherapy, ${ }^{2}$ brachytherapy, ${ }^{3}$ as well as intracerebrally implanted chemotherapeutic drugs. ${ }^{4}$ These treatments often require repeated surgical procedures, and are often associated with significant morbidity. Tamoxifen has been used extensively in the treatment of breast cancer. ${ }^{5}$ Its principal mode of action is as an antiestrogenic agent, but it has also been shown to have a series of estrogen independent actions ${ }^{6,7}$ including production of TGF $\beta,{ }^{8}$ as well as inhibition of protein kinase $C^{9-11}$ an important enzyme in signal transduction, ${ }^{12}$ which has been critically correlated with glioma cell proliferation in vitro. ${ }^{13,14}$ Indeed, treatment of established as well as low passage glioma cell lines in vitro can be inhibited by tamoxifen. ${ }^{15.16}$ Based on these studies, we began treating patients with recurrent gliomas with high dose tamoxifen, in order to attain high enough plasma levels to inhibit proliferation.

We report the case of a patient who is clinically stable, and demonstrates radiologic regression of a recurrent glioma, following one year of high dose tamoxifen therapy. Since tamoxifen has been demonstrated to be tolerable in high doses, it may be of potential benefit in the treatment of recurrent glioma.

\section{CASE REPORT}

The patient is a 43-year-old man, who had previously (1984) undergone a right temporal lobectomy with subtotal resection of a grade II fibrillary astrocytoma, followed by 6000 rads of cobalt adjuvant therapy. The patient was well (Figure 1A) until 15 months ago when he required a second anticonvulsant for seizure control. The CT scan (Figure 1B) revealed ring enhancement of the right fronto-parietal region with medial extension to the thalamo-capsular area. A followup $\mathrm{CT}$ scan one year ago demonstrated a new partially enhancing mass in the right frontal area causing mass effect and midline shift compatible with a recurrent high grade glioma (Figure IC). The patient had deteriorated clinically, with decreased intellectual function, slowed speech, and facial asymmetry. The lesion was considered inoperable because of its location, and the patient had already received maximal radiation therapy. The patient was started on dexamethasone $16 \mathrm{mg}$ per day which was maintained, and one week later, with informed patient consent, was started on high dose oral tamoxifen $180 \mathrm{mg}$ b.i.d. The patient has tolerated the treatment well, and is stable one year after commencing therapy. An infused CT scan and MRI with gadolinium (Figure ID,E) demonstrate that although the tumour is still present, in the last year there has been some regression in tumour size, with some decreased shift and mass effect.

\section{Discussion}

Tamoxifen has been used extensively in the treatment of breast cancer, and recently in high doses in the treatment of malignant melanoma. ${ }^{17}$ Although its primary action is via its antiestrogenic effect, it has other inhibitory effects including increasing transforming growth factor $\beta,{ }^{8}$ known to be inhibitory to selected cell lines, ${ }^{18}$ as well as inhibiting protein kinase $C,{ }^{9}$ an enzyme which is markedly elevated in glioma cell lines, and has been closely correlated with their proliferation. ${ }^{13,14}$ It has previously been demonstrated that tamoxifen could effectively inhibit glioma cell proliferation in nanomolar concentrations, ${ }^{15}$

Department of Neurology and Neurosurgery (G.B., J.G.V.), Department of Radiation Oncology (G.S.), Department of Oncology (A.L.), McGill University, Montreal

Received June 11, 1992. Accepted in final form November 16, 1992

Reprint requests to: Dr. Jean-Guy Villemure, Montreal Neurological Institute, 3801 University St., Montreal, Quebec, Canada H3A 2B4 


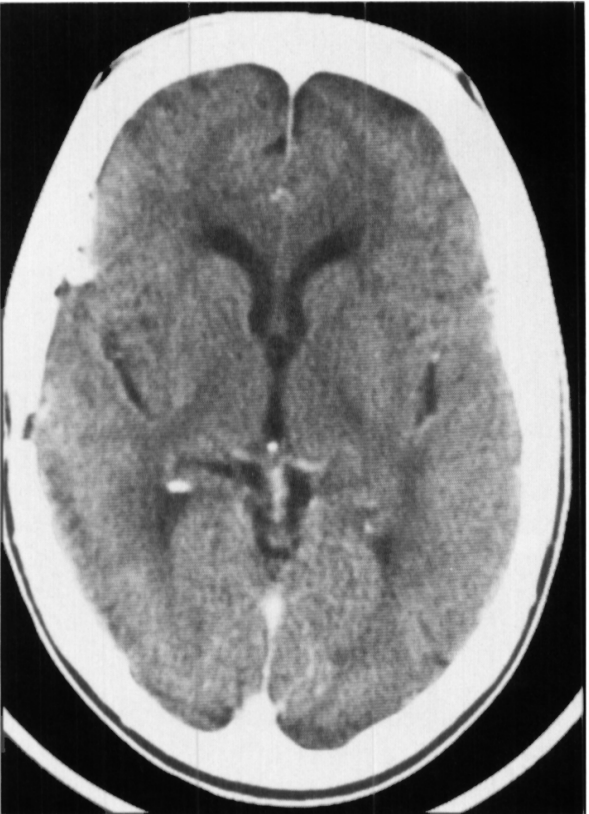

A



D

and based on these observations, Vertosick et al. have recently reported on a series of patients who had received maximal surgery and adjuvant radiation, as well as an "experimental" therapy ( i.e., brachytherapy, immunotherapy, or BCNU) with subsequent failure of these treatment modalities, who were treated with a conventional dose of tamoxifen $(40 \mathrm{mg} /$ day), without a dramatic response. ${ }^{19}$ We have recently confirmed the previous findings of Pollack et al., ${ }^{15.16}$ however we found that tamoxifen inhibited glioma cell proliferation in the micromolar vs. the nanomolar range. This micromolar range was also the concentration required to inhibit $\mathrm{PKC}$ in glioma cell protein extracts, ${ }^{16}$ and also corresponded to the concentration required to inhibit PKC in a cell free system. $9-11$ Based on these "in vitro" observations, we felt it was unlikely that a dose of $40 \mathrm{mg} / \mathrm{day}$

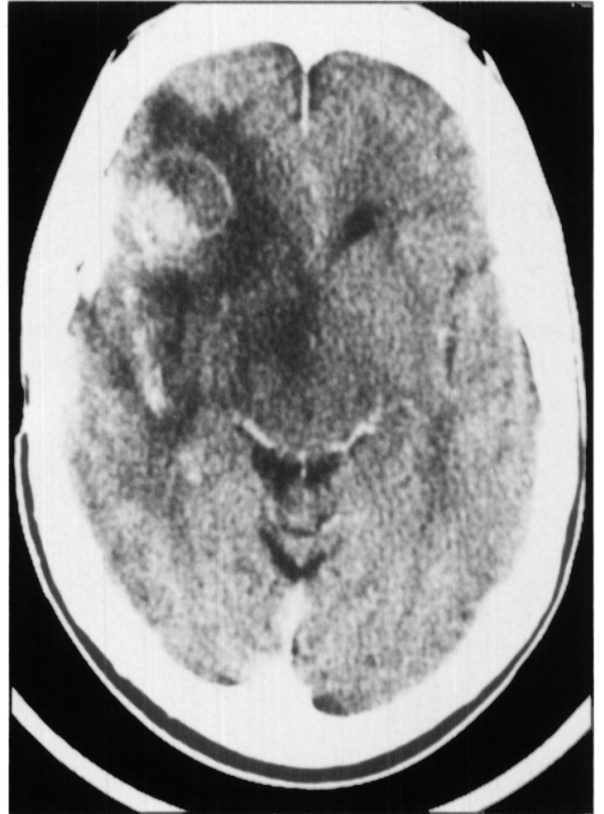

C

Figure I - (A) CT scan infused - 06/88 Status post right anterior temporal lobecto. my: with periventricular hypodensities likely secondary to radiation. $(B) C T$ scan infused 06/91 demonstrates a right fronto-parietal enhancing lesion with medial extrension to the right capsular thalmic region with mass effect and effacement of the third ventricle. (C) $C T$ (inf) 09/91. There is now a $3 \mathrm{~cm}$ partially enhancing mass with ring enhancement anteriorly in the right fromal region that was not present previously. There is an increase in the peritumoural edema with mild shift of midline structures to the left and mild conpression of the right frontal horn highly compatible with a recurrent malignant glioma. (D) CT (inf) 09/92. Demonstrates a decrease in enhancement and mass effect of the right frontal lesion. (E) MRI with Gadolinium 09/92. Demonstrates patchy peripheral enhancement around the right temporo-fronto-parietal mass. The enhancement is more pronounced posteriorly in the temporal lobe. would reach sufficient intracerebral level to effect inhibition of tumour proliferation.

Tamoxifen is known to cross the blood brain barrier and is well tolerated in doses of up to $150 \mathrm{mg} / \mathrm{m}^{2}$ b.i.d. ${ }^{17.21) \cdot 22}$ At doses of $120-150 \mathrm{mg} / \mathrm{m}^{2}$ b.i.d., the average tamoxifen plasma concentration was $3.2 \mu \mathrm{M}$, and its active metabolite $\mathrm{N}$-desmyl tamoxifen was $4.3 \mu \mathrm{M}$, the approximate concentration required for "in vitro" inhibition. 22 Given the "in vitro" observations, and recent reports of high dose tolerance, we treated this patient with recurrent glioma with tamoxifen $150 \mathrm{mg} / \mathrm{m}^{2}$ b.i.d., and observed clinical stabilization and radiologic tumour regression with a one year followup. Although we did not think it ethical to submit this patient to another surgical procedure to obtain a histological diagnosis for the purpose of a "medical" trial, and therefore can- 
not completely exclude the possibility that this recurrence represents radiation necrosis responsive to steroids, the appearance of this lesion seven years post radiation therapy makes the diagnosis of neoplasm much more likely.

Although this report represents only one case, and could therefore be considered anecdotal, we feel that the observation of tumour regression and clinical stabilization of a recurrent malignant glioma with a highly unfavourable prognosis, using a relatively non-toxic drug that is widely employed in the treatment of breast cancer, is significant. We hope that the Phase II trial presently in progress will demonstrate high dose oral tamoxifen to be beneficial in the treatment of recurrent glioma.

\section{ACKNOWLEDGEMENTS}

This work was presented at the Congress of Neurological Sciences of Quebec in Montreal, September 19, 1992. G.B. is a Fellow of the Medical Research Council of Canada.

\section{REFERENCES}

I. Barba D, Saris SC, Holder C, Rosenberg SA, Oldfield EH. Intratumoural LAK cell and interleukin-2 therapy of human gliomas. J Neurosurg 1989; 70: 175-182.

2. Mahaley MS, Hipp SW, Dropcho EJ, et al. Intracarotid cisplatinum chemotherapy for recurrent gliomas. J Neurosurg 1989; 70: 371 378.

3. Gutin PH, Leibel SA, Wara WM, et al. Recurrent malignant gliomas: survival following interstitial brachytherapy with highactivity iodine-125 sources. J Neurosurg 1987; 67: 864-873.

4. Brem H, Mahaley MS, Vick NA, et al. Interstitial chemotherapy with drug polymer implants for the treatment of recurrent gliomas. J Neurosurg 1991; 74: 441-446.

5. Legha SS, Tamoxifen in the treatment of breast cancer. Ann Intern Med 1988; 109: 219-228.

6. Rowlands MG, Parr IB, McGague R, et al. Variation of inhibition of calmodulin-dependent cyclic AMP phosphodiesterase amongst analogues of tamoxifen; correlates with cytotoxicity. Biochem Pharmacol 1990; 49: 283-289.

7. Sutherland RL, Murphy LC, Foo MS, et al. High affinity antiestrogen binding site distinct from the estrogen receptor. Nature 1980; 288: 273-275

8. Butta A, MacLennan K, Flanders KC, et al. Induction of transforming growth factor $\beta 1$ in human breast cancer in vivo following tamoxifen treatment. Cancer Res 1992; 52: 4261-4264.
9. O'Brian CA, Liskamp RM, Soloman DH, Weinstein IB, Inhibition of protein kinase C by tamoxifen. Cancer Res 1985; 45: 2462 2465.

10. Su HD, Mazzei GJ, Vogler WR, et al. Effects of tamoxifen, a nonsteroidal anti-estrogen on phospholipid/calcium-dependent protein kinase and phophorylation of its endogenous substrate proteins from rat brain and ovary. Biochem Pharmacol 1985; 34: 3649-3653.

11. Horgan K, Cooke E, Hallett MB, Mansel RE. Inhibition of proteinkinase $\mathrm{C}$ mediated signal transduction by tamoxifen. Biochem Pharmacol 1986; 35: 4463-4465.

12. Weinstein IB. The role of protein kinase $\mathrm{C}$ in growth control and the concept of carcinogenesis as a progressive disorder in signal transduction. Advances in second messenger and phosphoprotein research. 1990; 24: 307-316.

13. Couldwell WT, Uhm JH, Antel JP, Yong VW. Enhanced protein kinase $\mathrm{C}$ activity correlates with the growth of malignant glioma in vitro. Neurosurgery 1991; 29:880-887.

14. Couldwell WT, Antel JP, Yong VW. Enhanced protein kinase C activity correlates with the growth rate of malignant human gliomas. Effects of glioma mitogens and modulators of PKC. Neurosurgery 1992; 31: 717-724.

15. Pollack IF, Randall MS, Kristofik MP, et al. Effect of tamoxifen on DNA synthesis and proliferation of human malignant glioma lines in vitro. Cancer Res 1990; 50: 7134-7138.

16. Baltuch GH, Couldwell WT, Villemure J-G, Yong VW. Protein kinase $C$ inhibitors suppress cell growth in established and low passage glioma cell lines: a comparison between staurosporine and tamoxifen. Neurosurgery 1993 (in press).

17. Berd D, McLaughlin CJ, Hart E, et al. Short course high dose tamoxifen with cytotoxic chemotherapy for metastatic melanoma. Proc ASCO 1991; 10: 291.

18. Knabbe C, Lippman ME, Wakefield LM, et al. Evidence that TGF$\beta$ is a hormonally regulated negative growth factor in human breast cancer cells. Cell 1987; 48: 417-428.

19. Vertosick FT, Selker RG, Pollack IF, Arena V. The treatment of intracranial malignant gliomas using orally administered tamoxifen therapy: preliminary results in a series of "failed" patients. Neurosurgery 1992; 30: 897-903.

20. Corey RW, Davis JM, Zervas NT. Tamoxifen-induced regression of cerebral metastases in breast carcinoma. Cancer Treatment Rep 1981; 65: 793-795.

21. Hansen SB, Gulsgard H, Van Eyben FE, et al. Tamoxifen for brain metastases from breast cancer. Ann Neurol 1986; 20: 544.

22. Trump DL, Smith DC, Schold SC, et al. High dose tamoxifen and five day continuous infusion of vinblastine: a phase/trial of an inhibitor of the MDR-1 phenotype. Proc ASCO 1991; 10:96. 